\title{
PENGARUH MINAT SISWA ATAS MEDIA BELAJAR DAN PENGUASAAN KOSAKATA TERHADAP SPEAKING SKILL SISWA SMAN 2 KOTA JAMBI
}

\author{
PRISTO SIHOMBING \\ SMA Negeri 2 Kota Jambi Provinsi Jambi \\ brsihombingjambi@gmail.com
}

\begin{abstract}
ABSTRAK
Penelitian ini bertujuan untuk mengetahui pengaruh minat siswa atas media belajar dan penguasaan kosakata terhadap Speaking Skill bahasa Inggris siswa di SMA Negeri 2 Kota Jambi tahun pelajaran 2019/2020. Metode yang digunakan dalam penelitian ini adalah survey dengan analisis korelasi dan regresi, yaitu menghubungkan antara data yang menunjukkan tingkat minat siswa atas media belajar dan penguasaan kosakata dengan Speaking skill bahasa Inggris siswa di SMA Negeri 2 Kota Jambi tahun pelajaran 2019/2020. Pengambilan sampel dilakukan dengan teknik random sampling. Jumlah populasi 806 dengan responden dalam penelitian ini adalah 60 siswa. Instrumen penelitian yang digunakan adalah kuisioner dan soal tes dengan bentuk pilihan ganda. Hasil penelitian menunjukkan bahwa: 1) terdapat pengaruh yang signifikan minat siswa atas media belajar dan penguasaan kosakata secara bersama-sama terhadap Speaking skill bahasa Inggris siswa SMA Negeri 2 Kota Jambi tahun pelajaran 2019/2020. Hal ini dibuktikan dengan perolehan nilai Sig. 0,000 < 0,05 dan $\mathrm{Fh}=14,160$. Secara bersama-sama minat atas media belajar dan penguasaan kosakata memberikan kontribusi sebesar 33,2 \% terhadap variabel Speaking skill siswa. 2) terdapat pengaruh yang signifikan minat atas media belajar terhadap Speaking skill bahasa Inggris siswa SMA Negeri 2 Kota Jambi tahun pelajaran 2019/2020. Hal ini dibuktikan dengan perolehan nilai Sig. 0,013<0,05 dan th $=2,578$. Variabel minat atas media belajar memberikan kontribusi sebesar $14,32 \%$ dalam meningkatkan Speaking skill bahasa Inggris. 3) terdapat pengaruh yang signifikan penguasaan kosakata terhadap Speaking skill bahasa Inggris siswa SMA Negeri 2 Kota Jambi tahun pelajaran 2019/2020. Hal ini dibuktikan dengan perolehan nilai Sig. 0,003 < 0,05 dan th $=3,144$. Variabel penguasaan kosakata memberikan kontribusi sebesar 18,90\% dalam meningkatkan Speaking skill bahasa Inggris.
\end{abstract}

Kata Kunci: minat siswa, media belajar, penguasaan kosakata, speaking skill.

\section{PENDAHULUAN}

Pendidikan bagi tiap individu menjadi kebutuhan primer yang tidak bisa diabaikan begitu saja. Pendidikan dalam kehidupan menjadi point utama dalam menjalankan sendi kehidupan dan pergaulan sehari-hari, baik berupa pergaulan intelektual sampai dengan pergaulan perekonomian. Pendidikan yang baik dalam pengertian yang sederhana dapat didefinisikan sebagai usaha tiap individu dalam membangun kepribadiannya sesuai dengan nilai dan norma yang tumbuh di tengah masyarakat. Selanjutnya, pendidikan diartikan sebagai usaha yang dijalankan oleh seseorang atau kelompok orang lain agar menjadi dewasa atau mencapai tingkat hidup yang lebih tinggi dalam arti mental.

Pendidikan adalah usaha sadar dan terencana untuk mewujudkan suasana belajar dan proses belajar agar peserta didik secara aktif dapat mengembangkan potensi pada dirinya untuk dapat memiliki kekuatan spiritual, pengendalian diri, kecerdasan, akhlak mulia serta ketrampilan yang diperlukan dirinya, masyarakat, bangsa dan negara. Pendidikan pada dasarnya adalah suatu usaha yang dilakukan untuk membudayakan atau memberdayakan manusia agar menjadi pribadi yang mempunyai budi pekerti yang luhur.

Peningkatan kualitas sumber daya manusia merupakan salah satu penekanan dari tujuan pendidikan, seperti yang tertuang dalam Undang - Undang No. 20 Tahun 2003 tentang tujuan Pendidikan Nasional Bab II Pasal 3 yang berbunyi: "Pendidikan Nasional bertujuan mengembangkan speaking dan membentuk watak serta peradaban bangsa yang bermartabat dalam rangka mencerdaskan bangsa, bertujuan untuk berkembangnya potensi peserta didik agar 


\section{EDUCATOR : Jurnal Inovasi Tenaga Pendidik dan Kependidikan Vol. 1 No. 1 September 2021, e-ISSN : 2807-8659 | p-ISSN : 2807-8829}

menjadi manusia yang beriman dan bertaqwa kepada Tuhan Yang Maha Esa, berakhlak mulia, sehat, berilmu, cakap, kreatif, mandiri, dan menjadi warga negara yang demokratis serta bertanggung jawab". Dengan adanya undang-undang tersebut, maka pendidikan harus tetap menjadi prioritas utama untuk diusahakan kelengkapan sarana dan prasarananya terutama untuk sekolah. Salah satu tugas penting sekolah adalah menyiapkan siswa agar dapat mencapai perkembangannya secara optimal. Seorang siswa dikatakan dapat mencapai perkembangannya secara optimal apabila siswa dapat memperoleh pendidikan dan prestasi belajar yang sesuai dengan bakat, speaking dan minat yang dimilikinya.

Proses belajar mengajar di kelas bertujuan untuk mencapai perubahan-perubahan tingkah-laku intelektual, moral maupun sosial pada siswa. Siswa berinteraksi dengan media belajar diatur oleh guru melalui proses pembelajaran (Sukiyasa dan Sukoco, 2013). Proses pembelajaran yang terjadi di dalam kelas ditentukan oleh beberapa komponen pembelajaran, antara lain: tujuan pembelajaran, materi/bahan ajar, metode dan media, evaluasi, peserta didik/siswa, pendidik/guru (Toto Ruhimat, dkk., 2011: 147). Dengan demikian tentu harus diupayakan suatu proses pembelajaran yang dapat menjembatani berbagai faktor-faktor terutama kelemahan-kelemahan yang ada, agar tercapai tujuan pendidikan. Dalam penelitian ini salah satu variable yang difokuskan yakni komponen media belajar siswa. Media pembelajaran adalah suatu cara, alat, atau proses yang digunakan untuk menyampaikan pesan dari sumber pesan kepada penerima pesan yang berlangsung dalam proses pendidikan (Supardi, dkk, 2015). Media Pembelajaran dapat dibedakan menurut speakingnya membangkitkan rangsangan pada indra penglihatan, pendengaran, perabaan, penciuman dan pengecapan, sehingga secara umum ciri-ciri media pembelajaran adalah media itu dapat diraba, dilihat, didengar, dan diamati oleh panca indra, (Ankowo dan Kosasih, 2007:11).

Ditinjau dari sudut pandang pendidik, guru harus dapat mengintegrasikan speakingnya dalam mengelola pembelajaran di kelas, salah satunya bagaimana penggunaan media untuk mempermudah penyampaian materi, serta mempermudah penerimaan materi pelajaran oleh siswa. Dengan demikian, perlu upaya untuk menjembatani permasalahan tersebut demi tercapainya keberhasilan pengajaran. Jika pemilihan penggunaan media pembelajaran kurang tepat, maka akan menimbulkan masalah kepada para siswa yang berakibat minat dan motivasi belajar menjadi menurun. Hal ini disebabkan karena media pembelajarannya kurang menarik, apalagi kalau jumlah rata-rata siswa per kelas mencapai 40 atau 50 orang (Mutakin dan Sumiati, 2011). Selain itu perlu diingat pula bahwa, pada setiap diri siswa mempunyai minat belajar yang tidak sama antara siswa yang satu dengan yang lainnya, ada siswa yang minat belajarnya tinggi dan ada pula yang rendah. Oleh karena itu setiap guru harus dapat mengetahui minat belajar siswa dalam belajar agar minat belajar yang ada pada masing-masing siswa tergugah secara optimal untuk dapat meraih prestasi dalam belajar. Guru tidak hanya berfungsi sebagai pengajar melainkan juga harus berfungsi sebagai pendidik, pembimbing, pelatih dan pengarah bagi siswa-siswanya. Minat belajar siswa yang kuat pada diri siswa diyakini akan menyemangati siswa untuk berupaya keras dan pantang menyerah dalam menghadapi segala tantangan dan rintangan dalam belajar yang akhirnya akan menghasilkan prestasi yang berupa hasil belajar yang optimal.

Selain media belajar, penguasaan kosakata juga berpengaruh dalam speaking siswa skill bahasa Inggris. Bahasa dalam kehidupan sehari-hari sangat memegang peranan penting terutama dalam pengungkapan pikiran seseorang atau merupakan sarana untuk berpikir, menalar, menghayati kehidupan dan alat komunikasi. Hal ini sesuai dengan pendapat Keraf (1996:14), "bahasa adalah alat komunikasi antar anggota masyarakat yang berupa bunyi suara atau tanda atau lambang yang dikeluarkan oleh manusia untuk menyampaikan isi hatinya kepada manusia lainnya". Bahasa Inggris merupakan salah satu mata pelajaran wajib yang harus diikuti oleh semua siswa SMA sesuai dengan Permendiknas No.69 Tahun 2013 tentang kurikulum SMA. Pelajaran Bahasa Inggris yang diberikan meliputi empat aspek kebahasaan yaitu speaking mendengarkan (listening), skill (speaking), membaca (reading), dan menulis (writing). 


\section{EDUCATOR : Jurnal Inovasi Tenaga Pendidik dan Kependidikan Vol. 1 No. 1 September 2021, e-ISSN : 2807-8659 | p-ISSN : 2807-8829}

Dewasa ini kebutuhan untuk berbahasa Inggris semakin meningkat karena bahasa Inggris adalah bahasa Internasional yang sangat penting dalam era globalisasi. Banyak sekolah yang sudah mulai memberikan pembelajaran bahasa Inggris dari tingkat sekolah dasar (Lestari, 2012). Selain itu banyak sekali sekolah yang berbasis Internasional dimana bahasa Inggris digunakan sebagai bahasa pengantar. Bahasa Inggris yang digunakan oleh para siswa tidak lepas dari penguasaan kosakata, karena dengan penguasaan kosakata yang cukup akan memperlancar siswa dalam berkomunikasi dan mempermudah siswa untuk memahami bahasa yang terdapat dalam buku - buku pelajaran. Bahasa tidak akan terlepas dari belajar kosakata, karena kosakata merupakan aspek yang sangat penting dalam keterampilan berbahasa. Semakin banyak kosakata yang dihafal maka akan semakin terampil pula siswa dalam berbahasa (Nurfauziah, 2013). Dalam hal ini kosakata dapat meningkatkan pertumbuhan kegiatan menulis, skill, membaca dan menyimak (Tarigan, 1985: 85). Kosakata merupakan komponen yang memuat informasi yang berkaitan dengan pemakaian kata dalam Bahasa.

Pemahaman tentang kosa kata juga salah satu pemicu keberhasilah mempelajari bahasa Inggris sehingga semakin banyak kosa kata yang siswa pahami maka akan semakin mudah mereka dalam mengungkapkan ide yang ada pada pikiran mereka (Mulyana, dkk, 2018). Penguasaan kosakata pada usia SMA sangatlah penting dan merupakan bekal yang kuat untuk penguasaan kosakata pada usia kuliah dan selanjutnya. Siswa pada saat itu belajar dan dibimbing dengan teratur dan sistematik dalam proses menyadari dunia dan alam sekitarnya bahkan ke luar dunia alam sekitarnya yang disebut proses belajar.

Kenyataan di lapangan menunjukkan bahwa speaking skill bahasa Inggris pada siswa SMA umumnya masih rendah walaupun tingkat sekolah menengah atas karena pembelajaran siswa yang masih monoton, khususnya speaking dalam penguasaan kosakata mempunyai sebuah permasalahan yang serius yaitu belum terciptanya kebiasaan berkomunikasi dengan bahasa Inggris. Siswa pada umumnya lebih banyak menggunakan bahasa ibu, bahasa ibu dapat didefinisikan sebagai bahasa pertama yang dikuasai manusia sejak lahir melalui interaksi dengan sesama anggota masyarakatnya, seperti keluarga dan masyarakat medianya. Sangatlah sering dijumpai banyaknya siswa yang tidak dapat skill, memahami isi bacaan dan menulis dalam bahasa Inggris disebabkan karena mereka kurang perbendaharaan atau bahkan tidak tahu kosakata apa yang mereka harus ucapkan dan gunakan. Hal ini pula yang membuat mereka tidak dapat menyimak dengan baik apa yang disampaikan atau dikatakan oleh penutur asli maupun penutur lain yang menggunakan bahasa Inggris bahkan oleh gurunya sekalipun yang menyampaikan informasi, petunjuk atau pelajaran di kelas (Nappu, 2014).

Kurangnya penguasaan kosakata yang dimiliki oleh para siswa disebabkan oleh pembelajaran yang monoton terlihat pada saat mendeskripsikan sesuatu dalam bahasa Inggris kurang lancar, serta buku pelajaran yang kurang proporsional artinya belum mempunyai porsi yang cukup untuk mengembangkan keterampilan salah satunya berkomunikasi dengan menggunakan bahasa Inggris dengan baik dan benar.

\section{METODE PENELITIAN}

Penelitian ini dilaksanakan di SMA Negeri 2 Kota Jambi Provinsi Jambi. Alasan memilih SMA Negeri 2 Kota Jambi karena sekolah tersebut memiliki sarana dan prasarana yang menunjang serta memiliki perpustakaan sehingga dapat mendukung siswa dalam menguasai kosakata. Penelitian ini dilaksanakan selama 2 bulan mulai dari bulan Oktober sampai dengan November 2019. Jenis penelitian yang dilakukan dalam penelitian ini adalah penelitian kuantitatif dengan metode survei. Variabel penelitian ini terdiri dari variabel terikat, yaitu speaking skill bahasa Inggris (Y) dan dua variabel bebas, yaitu minat siswa atas media belajar (X1), dan Penguasaan kosakata (X2), maka model konstelasi hubungan antar variabel dalam penelitian ini adalah sebagai berikut : 


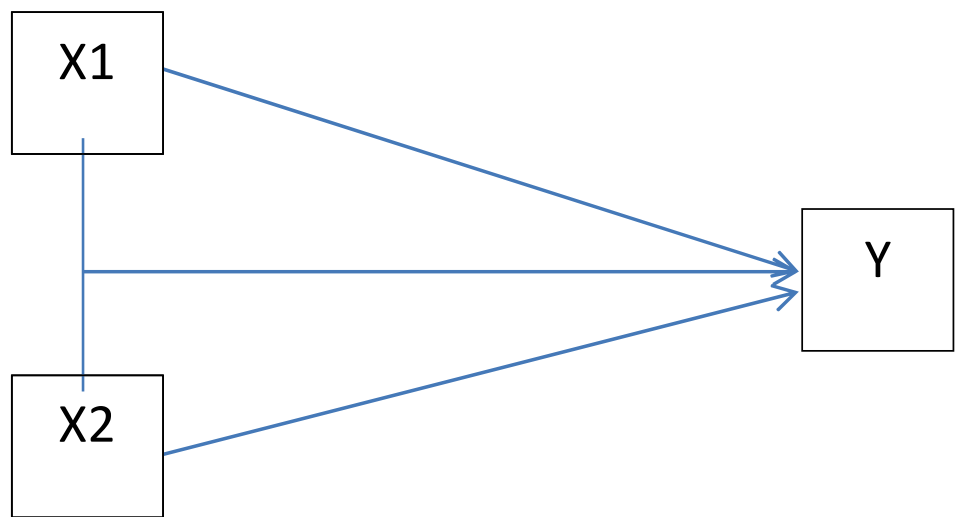

Keterangan:

$\mathrm{X} 1 \quad$ : Minat Siswa atas Media Belajar

X2 : Penguasaan Kosakata

$\longrightarrow \quad$ : Arah Pengaruh

Y : : Speaking speaking Bahasa Inggris

Adapun sampel dalam penelitian ini yakni siswa SMA Negeri 2 Kota Jambi tahun pelajaran 2019/2020 berjumlah 60 siswa. Instrument pengumpulan data berupa tes dan angket yang dibagikan kepada siswa. Dalam penelitian ini terdapat tiga variabel yaitu dua variabel bebas (X1dan X2) dan satu variabel terikat (Y). Variabel bebas pertama ialah media belajar (X1) dan variabel bebas kedua ialah penguasaan kosakata (X2), sebagai variabel terikatnya ialah speaking skill (Y).

\section{HASIL DAN PEMBAHASAN}

\section{Data Speaking Skill Bahasa Inggris.}

Data speaking skill bahasa Inggris diperoleh dari nilai tes 60 siswa yang menjadi sampel penelitian. Nilai yang di peroleh adalah terendah 58, tertinggi 98, rata- rata sebesar 80,72, median sebesar 80,00 modus sebesar 80 dan simpangan baku sebesar 8,663. Tabel 1. Deskripsi data Penelitian Speaking skill bahasa Inggris:

\begin{tabular}{lrr}
\hline \multicolumn{2}{c}{ Statistics } \\
\hline \multicolumn{2}{c}{ Speaking skill } & Bahasa Inggris \\
\hline $\mathrm{N}$ & Valid & 60 \\
\cline { 2 - 3 } & Missing & 0 \\
\hline Mean & 80.72 \\
\hline Median & 80.00 \\
\hline Mode & 80 \\
\hline Std. Deviation & 8.663 \\
\hline Minimum & 58 \\
\hline Maximum & 98
\end{tabular}

Bila dilihat dari hasil perhitungan di atas, maka bisa dikatakan bahwa speaking skill bahasa Inggris siswa tergolong cukup baik. Hal ini di indikasikan dengan perolehan skor ratarata sebesar 80,72 .

\section{Data Minat atas Media belajar (X1)}

Data minat atas media belajar diperoleh dari skor kuesioner yang di jawab oleh 60 siswa dihasilkan skor terendah 78, skor tertinggi 112, skor rerata sebesar 97,45, median 95,00 modus sebesar 95, dan simpangan baku sebesar 9,094. 
Tabel 2. Deskripsi data Penelitian minat atas media belajar

Statistics

\begin{tabular}{lrr}
\hline \multicolumn{3}{c}{ minat atas media belajar } \\
\hline \multirow{2}{*}{$\mathrm{N}$} & Valid & 60 \\
\cline { 2 - 3 } & Missing & 0 \\
\hline Mean & 97.45 \\
\hline Median & 95.00 \\
\hline Mode & 95 \\
\hline Std. Deviation & 9.094 \\
\hline Minimum & 78 \\
\hline Maximum & 112
\end{tabular}

Dari hasil perhitungan di atas, maka bisa dikatakan bahwa minat atas media belajar SMA Negeri 2 Kota Jambi tahun pelajaran 2019/2020 baik. Hal ini di indikasikan dengan perolehan skor rerata sebesar 97,45 di atas skor mediannya.

\section{Data Penguasaan kosakata (X2)}

Data penguasaan kosakata diperoleh dari nilai tes yang dijawab oleh 60 siswa sebagai responden dihasilkan nilai terendah 60 , nilai tertinggi 95 , nilai rerata sebesar 76,92 , median sebesar 75,00 modus sebesar 75 dan simpangan baku sebesar 9,210.

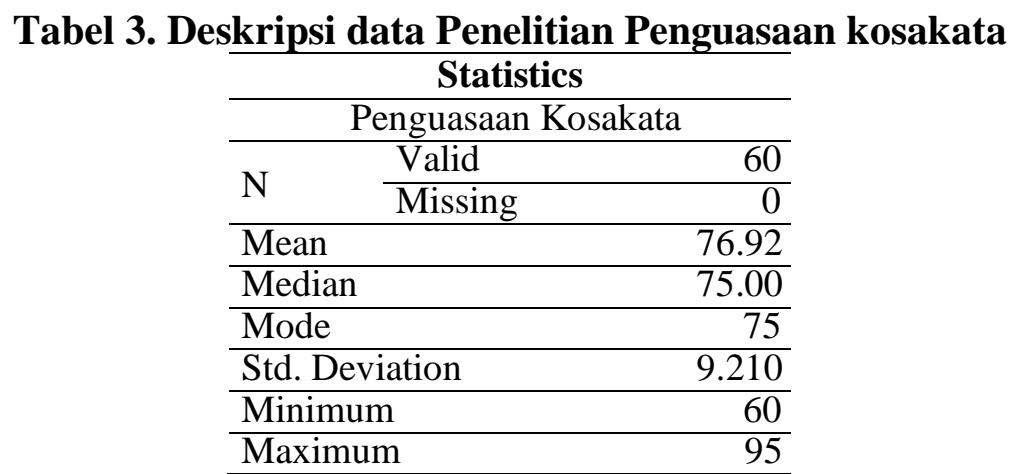

Dari hasil perhitungan di atas, maka bisa dikatakan bahwa penguasaan kosakata SMA Negeri 2 Kota Jambi tahun pelajaran 2019/2020 cukup baik. Hal ini diindikasikan dengan perolehan nilai rerata skor penguasaan kosakata 76,92.

Tabel 4. Uji Normalitas Data

\begin{tabular}{llrrr}
\hline & \multicolumn{4}{c}{ One-Sample Kolmogorov-Smirnov Test } \\
\hline & \multicolumn{1}{c}{$\begin{array}{c}\text { Seaking skill } \\
\text { Bahasa } \\
\text { Inggris }\end{array}$} & $\begin{array}{l}\text { Minat atas } \\
\text { Media Belajar }\end{array}$ & $\begin{array}{l}\text { Penguasaan } \\
\text { Kosakata }\end{array}$ \\
\hline $\mathrm{N}$ & \multicolumn{1}{c}{60} & 60 & 60 \\
\hline \multirow{2}{*}{$\begin{array}{l}\text { Normal } \\
\text { Parameters }\end{array}$} & Std. Deviation & 80.72 & 97.45 & 76.92 \\
\hline Most Extreme & Absolute & 8.663 & 9.094 & 9.210 \\
\cline { 2 - 5 } $\begin{array}{l}\text { Positive } \\
\text { Differences }\end{array}$ & Negative & .089 & .156 & .114 \\
\hline Kolmogorov-Smirnov Z & .075 & .156 & .102 \\
\hline Asymp. Sig. (2-tailed) & -.089 & -.110 & -.114 \\
\hline a. Test distribution is Normal. & .693 & 1.210 & .886 \\
\hline b. Calculated from data. & .722 & .107 & .412 \\
\hline
\end{tabular}

Dari table di atas menunjukkan bawha uji hipotesis yang menyatakan distribusi data pada analisis regresi ini mengikuti distribusi normal. Hal ini ditunjukkan dengan semua nilai Asymp. Sig > 0,05. Hal ini berarti semua data berdistribusi normal.

Pengajuan hipotesis dilakukan sesuai dengan ketentuan yang telah dijelaskan. Hasil perhitungan dan pengujian bisa dilihat pada table di bawah ini: 
Tabel 5. Hasil Perhitungan Pengujian Koefisien Korelasi Ganda Variabel X1 dan X2 terhadap Y Model Summary

\begin{tabular}{lcccc}
\hline Model & R & R Square & $\begin{array}{c}\text { Adjusted R } \\
\text { Square }\end{array}$ & $\begin{array}{c}\text { Std. Error of the } \\
\text { Estimate }\end{array}$ \\
\hline 1 & $.576^{\mathrm{a}}$ & .332 & .308 & 7.204 \\
\hline $\begin{array}{l}\text { a. Predictors: (Constant), Penguasaan Kosakata, minat atas } \\
\text { media Belajar }\end{array}$
\end{tabular}

Tabel 6. Hasil Perhitungan Pengujian Signifikansi Koefisien Regresi Variabel X1 dan X2

\begin{tabular}{|c|c|c|c|c|c|c|}
\hline \multicolumn{7}{|c|}{$\begin{array}{c}\text { terhadap Y } \\
\text { ANOVA }^{\mathbf{a}}\end{array}$} \\
\hline \multicolumn{2}{|c|}{ Model } & Sum of Squares & $\mathrm{df}$ & $\begin{array}{l}\text { Mean } \\
\text { Square }\end{array}$ & $\mathrm{F}$ & Sig. \\
\hline \multirow{3}{*}{1} & Regression & 1469.856 & 2 & 734.928 & 14.160 & $.000^{\mathrm{b}}$ \\
\hline & Residual & 2958.327 & 57 & 51.900 & & \\
\hline & Total & 4428.183 & 59 & & & \\
\hline \multicolumn{7}{|c|}{ a. Dependent Variable: speaking skill Bahasa Inggris } \\
\hline \multicolumn{7}{|c|}{$\begin{array}{l}\text { b. Predictors: (Constant), Penguasaan Kosakata, minat atas } \\
\text { media Belajar }\end{array}$} \\
\hline
\end{tabular}

Tabel 7. Hasil Perhitungan Persamaan Regresi Ganda Variabel X1 dan X2 terhadap Y

\begin{tabular}{|c|c|c|c|c|c|c|}
\hline \multirow{3}{*}{ Moc } & & \multicolumn{3}{|c|}{ Coefficients $^{a}$} & \multirow{3}{*}{$\mathrm{t}$} & \multirow{3}{*}{ Sig. } \\
\hline & & \multicolumn{2}{|c|}{$\begin{array}{c}\text { Unstandardized } \\
\text { Coefficients }\end{array}$} & \multirow{2}{*}{$\begin{array}{c}\text { Standardized } \\
\text { Coefficients } \\
\text { Beta }\end{array}$} & & \\
\hline & & B & Std. Error & & & \\
\hline \multirow{3}{*}{1} & (Constant) & 25.037 & 10.851 & & 2.307 & .025 \\
\hline & $\begin{array}{l}\text { Minat atas } \\
\text { Media } \\
\text { Belajar }\end{array}$ & 293 & .114 & .308 & 2.578 & .013 \\
\hline & $\begin{array}{l}\text { Penguasaan } \\
\text { Kosakata }\end{array}$ & .353 & .112 & .375 & 3.144 & .003 \\
\hline
\end{tabular}

a. Dependent Variable: speaking skill Bahasa Inggris

\section{KESIMPULAN}

Pada bagian kesimpulan ini, akan diuraikan secara singkat hasil penelitian yang diperoleh di lapangan dapat ditarik simpulan sebagai berikut: 1) Terdapat pengaruh yang signifikan minat atas media belajar dan penguasaan kosakata secara bersama-sama terhadap speaking skill bahasa Inggris siswa SMA Negeri 2 Kota Jambi Provinsi Jambi tahun pelajaran 2019/2020. Hal ini dibuktikan dengan perolehan nilai Sig. 0,000 <0,05 dan $\mathrm{Fh}=14,160$. Secara bersama-sama minat atas media belajardan penguasaan kosakata memberikan kontribusi sebesar 33,2 \% terhadap variable speaking skill bahasa Inggris. 2) Terdapat pengaruh yang signifikan minat atas media belajar terhadap speaking skill bahasa Inggris siswa SMA Negeri 2 Kota Jambi Provinsi Jambi tahun pelajaran 2019/2020. Hal ini dibuktikan dengan perolehan nilai Sig. 0,013 $<0,05$ dan th $=2,578$. Variabel minat atas media belaja rmemberikan kontribusi sebesar 14,32 \% dalam meningkatkan speaking skill bahasa Inggris. 3) Terdapat pengaruh yang signifikan penguasaan kosakata terhadap speaking skill bahasa Inggris siswa SMA Negeri 2 Kota Jambi Provinsi Jambi tahun pelajaran 2019/2020. Hal ini dibuktikan dengan perolehan nilai Sig. 0,003 $<0,05$ dan th $=3,144$. Variabel penguasaan kosakata memberikan kontribusi sebesar 18,90\% dalam meningkatkan speaking skill bahasa Inggris.

\section{DAFTAR PUSTAKA}

Angkowo R dan A Kosasih. (2007). Optimalisasi Media Pembelajaran, Jakarta: PT Grasindo. Keraf, G. (1996). Diksi dan gaya bahasa. Jakarta: Gramedia Pustaka Utama. 
Lestari, I. Y. (2012). Upaya Peningkatan Penguasaan Kosakata Bahasa Inggris Anak Melalui Media Kartu Gambar (Flash Card) Pada Kelompok B di RA Barokah Klodran Karanganyar Tahun Pelajaran 2011/2012 (Doctoral dissertation, Universitas Muhammadiyah Surakarta).

Mulyanah, E. Y., Ishak, I., \& Firdaus, M. I. (2018). Penerapan Metode Total Physical Response (TPR) Dalam Penguasaan Kosa Kata Bahasa Inggris Sekolah Dasar (SD). JPsd (Jurnal Pendidikan Sekolah Dasar), 4(2), 175-189.

Mutakin, T. Z., \& Sumiati, T. (2011). Pengaruh Penggunaan Media Belajar dan Minat Belajar terhadap Hasil Belajar Matematika (Eksperimen pada Siswa Kelas XI IPA SMA Negeri 8 Kota Tangerang Selatan Tahun Pelajaran 2010/2011). Formatif: Jurnal Ilmiah Pendidikan MIPA, 1(1).

Nappu, S. (2014). Peningkatan Penguasaan Kosakata Bahasa Inggris Siswa Melalui Pembelajaran Bahasa Berbantuan Komputer. JTP-Jurnal Teknologi Pendidikan, 16(3), 145-156.

Nurfauziah, L. (2013). Penggunaan teknik talking stick dalam meningkatkan penguasaan kosakata bahasa inggris anak usia dini (Doctoral dissertation, Universitas Pendidikan Indonesia).

Sukiyasa, K., \& Sukoco, S. (2013). Pengaruh media animasi terhadap hasil belajar dan motivasi belajar siswa materi sistem kelistrikan otomotif. Jurnal Pendidikan Vokasi, 3(1).

Supardi, S. U., Leonard, L., Suhendri, H., \& Rismurdiyati, R. (2015). Pengaruh media pembelajaran dan minat belajar terhadap hasil belajar fisika. Formatif: Jurnal Ilmiah Pendidikan MIPA, 2(1).

Tarigan, (1985). Kosakata Dalam Pembelajaran Bahasa. Bandung: Angkasa.

Toto Ruhimat, dkk. (2011). Kurikulum dan pembelajaran. Jakarta: Rajawali Pers. 